\title{
The Advanced Cultural Studies Institute of Sweden/ACSIS
}

\author{
A National Centre for Transnational \\ and Interdisciplinary Cultural Research
}

\author{
JOHAN FORNÄS
}

Since 2002, Sweden has a national centre for interdisciplinary cultural studies. This Advanced Cultural Studies Institute of Sweden (ACSIS) is located at Campus Norrköping of Linköping University. Its goal is to advance cultural research by critical and communicative engagement in order to forge interdisciplinary and transregional links, to develop and improve the quality of such research, and to strengthen the position of such studies in the academic community.

Mediatisation and globalisation belong to the key late modern tendencies that have contributed to change the place, role and function of cultural processes and practices. New cultural phenomena, patterns and problems have induced a need for new theoretical and methodological perspectives to grapple with previously neglected aspects of society and culture, including for instance technological, corporate and generic convergence, intermedial crossings and migrant media uses.

The famous international field of cultural studies was to a large extent born out of challenges for politics, everyday life, collective identities, citizenship and the public sphere that arose from the growth, spread and transformations of modern media culture. From its early days on, there are therefore great and fruitful overlaps between cultural studies and media studies, though they do of course not totally cover each other. Cultural studies is acting as an interdisciplinary clearing-house and critical forum within and between the humanities and social sciences (and increasingly also across to the natural sciences, medical and technological disciplines), "providing a useful interface at which the concerns of different disciplines, and of other interdisciplinary knowledges, can enter into fruitful forms of dialogue" (Tony Bennett (1998): "Cultural Studies: A Reluctant Discipline", Cultural Studies, 12:4).

This field has successfully expanded and spread all over the world. Its globalisation has inevitably resulted in differentiation and complexification, so that there are today many different regional variants beside the dominant British and American traditions. Time is ripe for the Nordic countries to make themselves heard more decisively in this field, in critical and creative mutual dialogues with others.

For the ACSIS, cultural studies involves all critical and interdisciplinary cultural research efforts, for which it strives to be a vital connective and progressive resource. The activities of this centre includes international fellowships, research, seminars, separate $\mathrm{PhD}$ courses and a wide range of communicative and informative networking.

The national character is institutionalised in a national ACSIS board, where each Swedish university rector has proposed one member. The initial board consists of professors Inge Jonsson (chair), Peter Aronsson (Linköping), Robert Burnett (Karlstad), Bernt Gustafsson (Örebro), Maths Isacson (Uppsala), Lisbeth Larsson (Göteborg), Britta Lundgren (Umeå), Orvar Löfgren (Lund), Mats Trondman (Växjö) and Helena Wulff (Stockholm). Activities are directed by professor Johan Fornäs and administred by $\mathrm{PhD}$ student Helene 
Egeland, both at the Department of Culture Studies, (Tema Q) of Linköping University.

The ACSIS web site http://www.acsis.liu.se has extensive English and Swedish information on all activities, as well as a section with worldwide links to other cultural studies sites. It presents all visiting scholars, seminars and courses on offer. It also includes information on how to subscribe to the Swedish-language e-mail based discussion and information list for cultural studies, "kulturstudier".

One important milestone for Swedish cultural studies is the first open national conference on this field, organised by PhD Bodil Axelsson for the ACSIS in Norrköping 13-15 June 2005. The conference language is Swedish, and this will be a first broad inventory over the scope and state of arts in Swedish cultural studies today, with ample opportunity to forge new links and take new initiatives for its future development, including plans for forming a more organised network to match those that since long exist in many other and neighbouring countries. The plenary programme includes lectures by board members among others on issues like concepts of culture, ethnography and textual analysis, temporal and spatial contexts, intersectional identities and critical perspectives. See the ACSIS web site for further information about the more than 30 sessions, covering most conceivable aspects of cultural studies today. It is notable that media and communication topics continue to have a prominent place in this field, and far from only represented by scholars located within the discipline of media and communication studies.

Activities during the first years have included seminars and workshops with board members and with visiting professors and young researchers on postdoc scholarships. Topics for previous workshops and seminars have included highly media-relevant issues like cultural industries and cultural policy, alternative media and cultural production, audiences and publics, television and media events, intermediality and textual analysis. Visitors include Daniel Dayan (France), Glen Fuller (Australia), Mikko Lehtonen (Finland), Brett Neilson (Australia), Justin O'Connor (UK), Roger Odin (France), Janice Radway (USA), Suruchi Thapar Björkert (UK/India), Lasse Thomassen (UK/Denmark), Keyan Tomaselli (South Africa) and John Urry (UK), as well as many Swedish scholars. Future visits and presentations are planned for Ien Ang (Australia), Mark Banks (UK), Lawrence Grossberg (USA), Keith Kahn-Harris (UK), Claudia Leeb (USA), Efvaris Mascha (UK), Sheenagh Pietrobruno (UK), Motti Regev (Israel), Geoff Stahl (Ger-
many/Canada) and Aagje Swinnen (Belgium), among others. There are also Swedish postdoc scholars and $\mathrm{PhD}$ students who with various individual grants visit this environment for some weeks' or months' studies and work. Provided continued funding is guaranteed, the postdoc grant programme will welcome further applications from all subfields of cultural studies and all world regions.

In general, thus, media and communications have a key role to ACSIS, mirroring the corresponding focal position both in and for cultural studies: as an increasingly central aspect of late modern culture and as a likewise increasingly important tool for interdisciplinary and transnational networking and bordercrossing. However, the ACSIS experience also testifies to the resistance and obstacles for any such transgressive venture. The centre was from the beginning a national initiative, and its initial establishment was made possible by grants from the state research council for humanities and social sciences (presently Vetenskapsrådet) and the Tercentary Foundation of the National Bank (Riksbankens Jubileumsfond). This national basis made it possible to receive also a welcome support from the municipality of Norrköping and most importantly from Linköping University. The formation of a national board is supposed to enable some kind of permanent national funding in the future, but at this moment, the resources for these ambitious and wide-ranging activities come from Linköping University, whose support covers basic resources to make possible at least a minimal level of visiting scholars and other tasks. The national research funds also support the national conference, but there is presently no other national funding available for keeping up the general work at this centre. This makes it increasingly difficult to uphold the aim to serve as a truly national resource for bridging gaps between universities, and it is also a severe threat to the future existence of ACSIS, since the host university has made it clear that their future support after three initial years is wholly dependent on additional external resources. Much work is therefore done to try and find ways to secure such external, national funding. This is not easy in times of scarce research resources for everyone, in particular for advanced basic research that does not easily lend itself to serve immediate external interests of corporations or other rich institutions outside the university system. It is particularly difficult for initiatives that aim to cross disciplinary as well as geographic borders. Single universities often have methods to support interdisciplinary co-operation within themselves, and there are on the other hand also ways to fund national networks within single disciplines. The Swedish funding 
system tends to make it extremely hard for those who try and build bridges in both directions simultaneously.

In spite of these problems, it is already clear that such a national centre meets a wonderful interest and demand among Swedish scholars, and that it will leave strong and lasting marks on cultural research. There is so much to be gained by spending limited resources on building networks and nodes for co-operation across partly outdated borders, and for intensifying transnational traffic and making Swedish cultural research more visible on a global scale. The ACSIS director happens to be also the vice-chair of the recently established international Association for Cultural Studies (ACS), and this di- rect link between the global field and the national arena will also be of great use in this work. ACSIS has established co-operation with several foreign research groups, including the Centre for Cultural Research at University of Western Sydney, with which a multifaceted exchange has been started. The range of such activities will grow steadily if the ACSIS is permitted to stay on, and it will benefit all surrounding universities through the policy to let each foreign visitor also make visits to other places and in other ways ensure that all activities are made to serve the widest possible range of sites around. The ACSIS is no closed haven, but a hub for intense crossroads, and it welcomes any suggestions how to further enrich these vitalising flows. 